\title{
Prevalence of Cytological Abnormalities in Papanicolaou Smears and Risk Factors for Cervical Cancer Among Women in Muscat, Oman
}

Eman Al Sekri, ${ }^{1}$ Asma Al Musalhi, ${ }^{1}$ Khadija Al Abri, ${ }^{1}$ Hunaina Al Kindi, ${ }^{2}{ }^{*}$ Asma A. Al Salmani ${ }^{3}$

\begin{abstract}
Objectives: This study aimed to estimate the prevalence of cytological abnormalities in Papanicolaou (Pap) smears and related risk factors among Omani women. Methods: A cross-sectional study was conducted from March to September 2019 at the gynaecology and family medicine clinics of Khoula Hospital and Sultan Qaboos University Hospital in Muscat. All asymptomatic Omani women aged between 21 and 65 years were included. Data regarding the participants' sociodemographic characteristics and known risk factors were collected using a selfreported sheet. Pap smears were performed and the results were reported by a cytotechnologist and histopathologist. Results: A total of 442 women participated in the study (response rate: 100\%). The mean age was $39.0 \pm 9.7$ years old. The prevalence of cervical cytological abnormalities was 3.7\%. There was a significant association between human papillomavirus (HPV) infection and cervical cell abnormalities ( $P=0.017$ ); however, there was no link with hormonal contraception use, pregnancy before the age of 17 years or parity $(P>0.050$ each). Conclusion: The prevalence of cervical cell abnormalities in Oman was similar to that observed in Arab countries and relatively low in comparison to findings from Western countries. A screening program should be implemented at the primary care level. The findings of this study also highlighted the need for a future vaccination program against HPV infections.
\end{abstract}

Keywords: Cervical Cancer; Screening; Pap Smear; Human Papillomavirus; Oman.

\section{AdVANCES IN KNOWLEDGE}

The prevalence of cervical cell abnormalities in Oman was similar to that observed in Arab countries and relatively low in comparison to findings from Western countries.

There is a significant association between cervical cell abnormalities and human papillomavirus (HPV) infection.

\section{Applications to Patient Care}

The findings related to the prevalence of cervical cell abnormalities suggested that women should visit their gynaecology/family medicine clinic for cervical cancer screening using a Pap smear.

Women with a history of HPV infection need to be screened for the early detection of cervical cell abnormalities.

A

FTER CARDIOVASCULAR EVENTS, CANCER IS the leading cause of mortality worldwide due to increasing population growth and life expectancy. ${ }^{1,2}$ In 2018, cervical cancer was one of seven cancers that together represented half of the annual global incidence and mortality burden of all cancers; moreover, this type of cancer ranked fourth in both incidence and mortality among female cancers, with 570,000 cases and 311,000 deaths. ${ }^{1}$ Worldwide, the distribution of cervical cancer cases varies according to region, with the highest rate reported in sub-Saharan Africa and Southeast Asia; in contrast, incidence rates are 7-10 times lower in Western Asia. ${ }^{3}$ In Oman, cervical cancer is the third most frequent cancer among women, with an average of 77 new diagnoses and 41 deaths reported every year. ${ }^{4}$

Various risk factors have been established in relation to cervical cancer, including smoking, age at first intercourse, number of sexual partners and duration of oral contraceptive use. $^{5-7}$ In particular, human papillomavirus (HPV) infection plays a major causative role. ${ }^{8}$ Cervical cancer is slow-progressing, and it can take up to 10 years or more for the precancerous cells to become malignant; however, affected cases can be detected sufficiently early, thus improving outcomes. ${ }^{9}$ The most common screening method for cervical cancer is Papanicolaou (Pap) smear cytology, which is the cornerstone for cervical cancer screening guidelines. ${ }^{10}$ However, while these risk factors have been studied extensively in Western populations, inconsistent results have been reported from countries in the Arabian Gulf region, including different patterns and prevalence rates of cervical cytological abnormalities and other cervical cancer risk factors. ${ }^{11-13}$

Significant declines in cervical cancer cases have been reported following the introduction of cervical cancer screening and HPV vaccine programmes; in 
the UK, the incidence rate decreased by $24 \%$, while cervical cancer fell from the top 10 to 14th place in terms of cancer-related deaths in the USA. ${ }^{14-16}$ Unfortunately, up to $85 \%$ of global deaths due to cervical cancer occur in developing countries, which can be attributed to the lack of structured screening and HPV vaccine programmes as well as inadequate awareness and knowledge regarding cervical cancer and the importance of routine screening among members of the public. ${ }^{17,18}$ Hence, this study aimed to estimate the prevalence of cervical cytological abnormalities and explore cervical cancer risk factors in an asymptomatic Omani population.

\section{Methods}

This cross-sectional study was conducted between March and September 2019 at the Khoula Hospital and Sultan Qaboos University Hospital in Muscat, Oman. All asymptomatic Omani women aged between 21 and 65 years old who attended the gynaecology or family medicine clinics of these hospitals during the study period were included. However, women who were symptomatic (i.e. presenting with vaginal discharge, lower abdominal pain, postcoital bleeding or intermenstrual bleeding) and those diagnosed with cervical or uterine cancer were excluded. Based on a prevalence rate of $2.6 \%$ at a $95 \%$ significance level and taking into consideration a two-sided alpha value of $5 \%$ and a $2 \%$ margin of error, the necessary sample size was calculated to be 442 participants.

Trained staff in each hospital distributed the data collection sheet after obtaining consent from participants. All participants filled out an information sheet for the assessment of their sociodemographic characteristics and risk factors, including their age, marital status, number of sexual partners, number of children, history and duration of hormonal contraceptive use, whether they had been pregnant before the age of 17 years, history of HPV vaccination or infection, smoking history and family history of cervical cancer. For illiterate participants, the investigators transcribed verbal responses to each of the questions on the information sheet.

Subsequently, the women underwent a routine Pap smear performed by a physician. Cellular material was collected using one of two methods. The first method involved placing the long edge of an Ayre spatula on the cervix near the squamocolumnar junction and rotating it $360^{\circ}$; the cellular material was then gently smeared on a clean glass slide and immediately fixed with 95\% ethyl alcohol (conventional method). The other method involved brushing the cervix with a cervical cytology brush before placing the tool in a BD SurePath ${ }^{\text {TM }}$ liquid-based Pap test (Becton, Dickinson \& Co., Franklin Lakes, NJ, USA). The cytology of the cervical samples was analysed by a cytotechnologist according to the 2014 Bethesda classifications, with all abnormal results being reviewed by a histopathologist. ${ }^{19}$ The results of the Pap smear were then recorded in the patient's medical records and subsequently accessed by the investigators via the electronic hospital information systems.

Data were analysed using the Statistical Package for the Social Science (SPSS), Version 20 (IBM Corp., Armonk, NY, USA). Continuous variables were presented as means with standard deviation, while categorical variables were reported as frequencies and percentages. The prevalence of cytological abnormalities in Pap smears was presented as a percentage. Associations between cervical cell abnormalities and risk factors of cervical cancer were assessed using a Chi-squared test. For cells with low frequencies, Fisher's exact tests were used. The level of statistical significance was set at $P<0.050$.

This study was approved by the Research and Ethical Review and Approval Committee of the Ministry of Health as well as the Medical Research Ethics Committee of the College of Medicine \& Health Sciences, Sultan Qaboos University. All participants signed a written consent form after being informed that involvement in this study would not affect their treatment. The confidentiality of the information collected was maintained at all times; moreover, the participants were aware of their right to withdraw from the study at any point.

\section{Results}

A total of 442 women participated in this study (response rate: 100\%), with an equal number of participants from Khoula Hospital and Sultan Qaboos University Hospital. The mean age of the women was $39.0 \pm 9.7$ years, with $43.9 \%(n=194)$ aged between 36 and 50 years, $42.3 \%(n=187)$ aged between 21 and 35 years and $13.8 \%(n=61)$ aged between 51 and 65 years. The vast majority (95.7\%; $n=423$ ) of the participants were married. In terms of parity, 50.5\% $(n=223)$ had three or more children, $26.5 \%(\mathrm{n}=117)$ had less than three children and $23.1 \%(\mathrm{n}=102)$ were nulliparous. Only 25 women (5.7\%) reported having been pregnant before the age of 17 years. Overall, 86.4\% had never used hormonal contraceptives; among those who had, $35 \%(n=21)$ reported the duration of their use to be under a year. None of the women was a smoker or had previously received the HPV vaccine. A positive family 
Table 1: Sociodemographic characteristics and cervical cancer risk factors among Omani women who underwent Papanicolaou smear testing $(\mathrm{N}=442)$

$\begin{array}{lc}\text { Characteristic/Risk Factor } & \text { n (\%) } \\ \text { Age in years } & \\ 21-35 & 187(42.3) \\ 36-50 & 194(43.9) \\ 51-65 & 61(13.8)\end{array}$

\section{Marital status}

Married

$423(95.7)$

Divorced

Widowed

Pregnancy before 17 years of age

Yes

No

Hormonal contraception use

Yes

No

$382(86.4)$

Duration of hormonal contraception in months*

$$
<12
$$

$$
13-24
$$

$25-60$

$>61$

\section{Number of children}

0

$1-3$

$>3$

\section{Smoking status}

Yes

No

\section{History of HPV infection}

Yes

No

Vaccinated against HPV

Yes

No

Family history of cervical cancer

Yes

No

$440(99.6)$

$H P V=$ Human papillomavirus.

"Percentages for this variable have been calculated out of the total number of women who reported having ever used hormonal contraception.
Table 2: Frequency of cervical epithelial cell abnormalities among Omani women who underwent Papanicolaou smear testing $(\mathrm{N}=442)$

\begin{tabular}{lc} 
Type of Abnormality & $\mathbf{n}(\%)$ \\
\hline ASCUS & $8(1.8)$ \\
LSIL & $6(1.4)$ \\
SCC & $2(0.5)$ \\
None & $426(96.4)$
\end{tabular}

ASCUS = Atypical squamous cells of undetermined significance; $L S I L=L o w-$ grade squamous intraepithelial lesion; $S C C=$ Squamous cell carcinoma .

Table 3: Relationship between cervical cancer risk factors and cervical epithelial cell abnormalities among Omani women who underwent Papanicolaou smear testing $(\mathrm{N}=442)$

$\begin{array}{lcrl}\text { Risk Factor } & \begin{array}{r}\text { Cervical Epithelial Cell } \\ \text { Abnormalities n (\%) }\end{array} & \text { P value } \\ \text { Yes }(\mathbf{n}=16) & \text { No }(\mathbf{n}=426) & \\ \text { Age group in years* } & & \\ 21-35 & 9(4.8) & 178(95.2) & \\ 36-50 & 6(3.1) & 188(96.9) & 0.449 \\ 51-65 & 1(1.6) & 60(98.4) & \end{array}$

History of HPV infection

$\begin{array}{cccc}\text { Yes } & 2(12.5) & 4(0.9) & 0.017 \\ \text { No } & 14(87.5) & 422(99.1) & \end{array}$

Pregnancy before 17 years of age

$\begin{array}{lccc}\text { Yes } & 0(0) & 25(5.9) & \\ \text { No } & 16(100) & 401(94.1) & 1.000\end{array}$

\section{Hormonal contraception use}

$\begin{array}{lll}\text { Yes } & 1(6.3) & 60(14.1)\end{array}$

0.700

No $\quad 15(93.8) \quad 366(85.9)$

Parity status

$\begin{array}{llll}\begin{array}{l}\text { Primiparous/ } \\ \text { multiparous }\end{array} & 2(12.5) & 100(23.5) & \\ & & 0.380\end{array}$

Nulliparous $\quad 14(87.5) \quad 326(76.5)$

Family history of cervical cancer

$\begin{array}{cccc}\text { Yes } & 0(0) & 2(0.5) & \\ \text { No } & 16(100) & 424(99.5) & 1.000\end{array}$

HPV = Human papillomavirus.

"The percentages were calculated out of the total of each age group.

history of cervical cancer was reported by two women (0.5\%) and six women were positive for previous HPV infections (1.4\%) [Table 1].

Based on the Pap smear results, the overall prevalence rate of cervical cytological abnormalities during the study period was $3.7 \%$. The most frequent 
epithelial cell abnormalities were atypical squamous cells of undetermined significance (ASCUS; 1.8\%), followed by low-grade squamous intraepithelial lesions (LSILs; 1.4\%) and squamous cell carcinoma (SCC; 0.5\%) [Table 2]. The frequency of abnormal cervical cytology was significantly higher in women with previous HPV infections $(P=0.017)$. However, no significant association was observed between abnormal Pap smear results and other risk factors for cervical cancer, including age, hormonal contraceptive use, pregnancy before the age of 17 years, a family history of cervical cancer or parity [Table 3].

\section{Discussion}

This study aimed to detect the prevalence and characteristics of cervical epithelial cell abnormalities among Omani women who underwent Pap smear testing. According to the 2014 Bethesda system, the overall prevalence of cervical cytological abnormalities was $3.7 \% .^{19}$ This rate was similar to those reported in neighbouring Gulf countries, including Kuwait (4.4\%), Saudi Arabia (4.3\%) and the United Arab Emirates (UAE; 3.6\%). ${ }^{11,12,20}$ Comparable rates have also been reported in Jordan (3.8\%), Turkey (2.8\%) and Iran (4.0\%). ${ }^{21-23}$ These consistently low rates align with research that indicates that the lowest incidence of cervical cancer globally is observed in Western Asia. ${ }^{24}$ This is likely due to the highly conservative culture in this region, with most countries being predominantly Islamic, thereby limiting the prevalence of sexual behaviours that add to the potential risk.

In the current study, no cases of high-grade squamous intraepithelial lesions were noted. Previous research has confirmed that ASCUS is the most common type of epithelial cell abnormality observed in Kuwait (2.37\%), the UAE (2.5\%) and Saudi Arabia (2.9\%). ${ }^{11,12,20}$ However, the prevalence of ASCUS was much lower among Omani women in the present study $(1.8 \%)$. On the other hand, the rates of both LSILs (1.4\%) and SCC (0.5\%) were higher compared to studies from Kuwait (0.9\% and 0.09\%, respectively) and Southwestern Saudi Arabia (1.3\% and 0.3\%, respectively). ${ }^{12,25}$

Persistent HPV infection increases the risk of progression from precancerous cervical lesions to invasive cancer. ${ }^{26}$ In the present study, a history of HPV infection was significantly associated with the risk of intraepithelial abnormalities $(P=0.017)$. In developed countries, the implementation of HPV vaccine programmes and cervical cytology screening has reduced cervical cancer-related mortality by $50-75 \%$ over the past 50 years. ${ }^{26}$ The World Health
Organization recommends that women undergo cervical cancer screening at least once before the age of 45 years. ${ }^{27}$ Indeed, research has shown that most epithelial cell abnormalities are diagnosed in women aged 45 years or older. ${ }^{28}$ In the present study, the mean age of the women undergoing Pap smears was 39 years, thus indicating that this population was a suitable target for cervical cancer screening.

However, apart from a history of HPV infection, no association was observed between intraepithelial abnormalities and the prevalence of other established risk factors for cervical cancer; this finding suggested that Omani women may display different characteristics compared with other populations. For example, none of the participants was a smoker; in the Gulf Cooperation Council region, smoking is linked to many types of cancer, including cervical cancer. ${ }^{29}$ Moreover, oral contraceptive use is associated with an increased risk of developing cervical intraepithelial abnormalities. ${ }^{30}$ In contrast, no significant relationship with this variable was observed in the current study. In addition, there were no significant differences for other variables that have been traditionally linked to cervical cancer, such as a family history of the disease, pregnancy before the age of 17 years or parity.

This research has some limitations, particularly with regard to its nature. The participants were recruited from two tertiary hospitals in Muscat, thereby limiting the generalisability of the results on a national level. However, as these hospitals are visited by women from all over the country and the characteristics of the cohort reflected those of the general population, these concerns are negligible. In addition, collection of the cervical cell samples for cytology was done using two disparate methods (i.e. conventional and liquid-based techniques); nevertheless, there was no significant difference in sampling efficacy or analysis between the two methods. Future research is recommended to investigate the suitability and cost-effectiveness of different screening methods for preventable causes of cervical cancer, such as the identification and genotyping of HPV infections. Such screening may highlight the need for a national HPV vaccination programme to reduce the incidence and mortality burden of cervical cancer in Oman.

\section{Conclusion}

This study aimed to assess the prevalence of cytological abnormalities in Pap smears and the risk factors for cervical cancer among a cohort of Omani women. Although the overall prevalence of cervical epithelial cell abnormalities was low, there was a significant 
association with a history of HPV infection but not with other commonly established cervical cancer risk factors. Thus, there is a need for additional research to evaluate the cost-effectiveness of preventive strategies and encourage the early detection of precancerous cervical cells. In particular, national HPV screening and vaccination programmes, which have been successfully implemented in many other countries, may represent a suitable avenue for reducing the burden of cervical cancer in Oman.

\section{CONFLICT OF INTEREST}

The authors declare no conflicts of interest.

\section{FUNDING}

No funding was received for this study.

\section{ACKNOWLEDGEMENTS}

The authors would like to thank the Deputy of Research at SQUH and $\mathrm{KH}$ for their contribution and collaboration in our study and women for their participation

\section{AUTHORS' CONTRIBUTION}

ES, AM, KA and AAS conceptualised and designed the study. ES, AM, KA and HK collected the data. ES, AM, KA HK and AAS analysed and interpreted the results. ES, AM, KA and HK drafted the manuscript. All authors reviewed the results and approved the final version of the manuscript.

\section{References}

1. Bray F, Ferlay J, Soerjomataram I, Siegel RL, Torre LA, Jemal A. Global cancer statistics 2018: GLOBOCAN estimates of incidence and mortality worldwide for 36 cancers in 185 countries. CA Cancer J Clin 2018; 68:394-424. https://doi. org/10.3322/caac.21492.

2. Fidler MM, Bray F, Soerjomataram I. The global cancer burden and human development: A review. Scand J Public Health 2018; 46:27-36. https://doi.org/10.1177/1403494817715400.

3. Ferlay J, Soerjomataram I, Dikshit R, Eser S, Mathers C, Rebelo M, et al. Cancer incidence and mortality worldwide: Sources, methods and major patterns in GLOBOCAN 2012. Int J Cancer 2015; 136:E359-86. https://doi.org/10.1002/ijc.29210.

4. ICO/IARC Information Centre on HPV and Cancer. Oman: Human papillomavirus and related cancers, fact sheet 2021. Barcelona: HPV Information Centre. From: https://hpvcentre. net/statistics/reports/OMN_FS.pdf Accessed: Sept 2020.

5. Jhingran A, Russel AH, Seiden MV, Duska LR, Goodman A, Lee SL, et al. Cancers of the cervix, vulva, and vagina. In: Niederhuber JE, Armitage JO, Doroshow JH, Kastan MB, Tepper JE. Abeloff's Clinical Oncology, 6th ed. Netherlands: Elsevier, 2019. Pp.1468-507. https://doi.org/10.1016/B978-14557-2865-7.00087-4.

6. Ngelangel C, Muñoz N, Bosch FX, Limson GM, Festin MR, Deacon J, et al. Causes of cervical cancer in the Philippines: A case-control study. J Natl Cancer Inst 1998; 90:43-9. https:// doi.org/10.1093/jnci/90.1.43.
7. Green J, Berrington de Gonzalez A, Sweetland S, Beral V, Chilvers C, Crossley B, et al. Risk factors for adenocarcinoma and squamous cell carcinoma of the cervix in women aged 20-44 years: the UK National case-control study of cervical cancer. Br J Cancer 2003; 89:2078-86. https://doi.org/10.1038/ sj.bjc. 6601296 .

8. Bosch FX, Lorincz A, Muñoz N, Meijer CJ, Shah KV. The causal relation between human papillomavirus and cervical cancer. J Clin Pathol 2002; 55:244-65. https://doi.org/10.1136/ jcp.55.4.244.

9. Koss LG, Stewart F, Foote FW, Jordan MJ, Bader GM, Day E. Some histological aspects of behavior of epidermoid carcinoma in situ and related lesions of the uterine cervix. A long-term prospective study. Cancer 1963; 16:1160-211. https://doi.org/1 0.1002/1097-0142(196309)16:9<1160::aid-cncr28201609 $10>3.0 . c 0 ; 2-4$.

10. Ugboma HAA, Aburoma HLS. Pap smear: An important screening technique for preventing and detecting cervical cancer. Continental J Med Res 2010; 4:13-17. http://doi. org/10.5281/zenodo.3528011.

11. Ghazal-Aswad S, Gargash H, Badrinath P, Al-Sharhan MA, Sidky I, Osman N, et al. Cervical smear abnormalities in the United Arab Emirates: A pilot study in the Arabian Gulf. Acta Cytol 2006; 50:41-7. http://doi.org/10.1159/000325893.

12. Kapila K, Sharma PN, George SS, Al-Shaheen A, Al-Juwaiser A, Al-Awadhi R. Trends in epithelial cell abnormalities observed on cervical smears over a 21-year period in a tertiary care hospital in Kuwait. Sultan Qaboos Univ Med J 2015; 15:e112-15.

13. Balaha $\mathrm{MH}, \mathrm{Al}$ Moghannum MS, Al Ghowinem N, Al Omran S. Cytological pattern of cervical Papanicolaou smear in eastern region of Saudi Arabia. J Cytol 2011; 28:173-7. http://doi. org/10.4103/0970-9371.86343.

14. Cancer Research UK. Cervical cancer statistics. London: Cancer Research UK, 2020. From: https://www.cancerresearchuk.org/ health-professional/cancer-statistics/statistics-by-cancer-type/ cervical-cancer/incidence $\% 23$ heading-Ten\#heading-Zero Accessed: Sept 2020.

15. Peto J, Gilham C, Fletcher O, Matthews FE. The cervical cancer epidemic that screening has prevented in the UK. Lancet 2004; 364:249-56. http://doi.org/10.1016/S0140-6736(04)16674-9.

16. Siegel R, Naishadham D, Jemal A. Cancer statistics, 2012. CA Cancer J Clin 2012; 62:10-29. http://doi.org/10.3322/caac.20138.

17. United Nations Population Fund. Comprehensive cervical cancer prevention and control: Programme guidance for countries. From: https://www.unfpa.org/resources/comprehensivecervical-cancer-prevention-and-control-programmeguidance-countries Accessed: Sept 2020.

18. Nasar A, Waad A, Atheer A, Nasra A. Awareness of cervical cancer and Pap smear testing among Omani women. Asian Pac J Cancer Prev 2016; 17:4825-30. http://doi.org/10.22034/ APJCP.2016.17.11.4825

19. Solomon D, Davey D, Kurman R, et al. The 2001 Bethesda System: Terminology for reporting results of cervical cytology. JAMA 2002; 287:2114-19. http://doi.org/10.1001/jama.287.16.2114.

20. Al-Kadri HM, Kamal M, Bamuhair SS, Omair AA, Bamefleh HS. Prevalence and characteristics of abnormal Papanicolaou smear in Central Saudi Arabia. Saudi Med J 2015; 36:117-22. http://doi.org/10.15537/smj.2015.1.9141.

21. Maraqa B, Lataifeh I, Otay L, Badran O, Nouri YQ, Issam I, et al. Prevalence of abnormal Pap smears: A descriptive study from a cancer center in a low-prevalence community. Asian Pac J Cancer Prev 2017; 18:3117-21. http://doi.org/10.22034/ APJCP.2017.18.11.3117.

22. Atilgan R, Celik A, Boztosun A, Ilter E, Yalta T, Ozercan R. Evaluation of cervical cytological abnormalities in Turkish population. Indian J Pathol Microbiol 2012; 55:52-5. http://doi. org/10.4103/0377-4929.94856. 
23. Maleki A, Ahmadnia E, Avazeh A, Mazloomzadeh S, Molaei B, Jalilvand A. Prevalence of abnormal Papanicolaou test results and related factors among women living in Zanjan, Iran. Asian Pac J Cancer Prev 2015; 16:6935-9. http://doi.org/10.7314/ apjcp.2015.16.16.6935.

24. Arbyn M, Weiderpass E, Bruni L, de Sanjosé S, Saraiya M, Ferlay J, et al. Estimates of incidence and mortality of cervical cancer in 2018: A worldwide analysis. Lancet Glob Health 2020; 8:e191-203. http://doi.org/10.1016/S2214-109X(19)30482-6.

25. Elhakeem HA, Al-Ghamdi AS, Al-Maghrabi JA. Cytopathological pattern of cervical Pap smear according to the Bethesda system in Southwestern Saudi Arabia. Saudi Med J 2005; 26:588-92.

26. zur Hausen H. Papillomaviruses and cancer: From basic studies to clinical application. Nat Rev Cancer 2002; 2:342-50. http:// doi.org/10.1038/nrc798.
27. World Health Organization. The Global Health Observatory: Cervical cancer screening. Geneva: World Health Organization. From:https://www.who.int/health-topics/cervical-cancer\#tab= tab_1 Accessed: Sept 2020.

28. Banik U, Bhattacharjee P, Ahamad SU, Rahman Z. Pattern of epithelial cell abnormality in Pap smear: A clinicopathological and demographic correlation. Cytojournal 2011; 8:8. http://doi. org/10.4103/1742-6413.80527.

29. Al-Zalabani $\mathrm{AH}$. Cancer incidence attributable to tobacco smoking in GCC countries in 2018. Tob Induc Dis 2020; 18:18. http://doi.org/10.18332/tid/118722.

30. Brabin L, Barr F. Oral contraceptives and cervical cancer. Lancet 2002; 360:409-10. http://doi.org/10.1016/S0140-6736(02)09577-6. 